\title{
THE PLACE OF PALLIATIVE MULTIVISCERAL RESECTIONS FOR LOCALLY ADVANCED COLORECTAL CANCER
}

\author{
Vesselin Marinov \\ Minimally Invasive and Laparoscopic Surgery, HPB and General Surgery Clinic, \\ Tokuda Hospital Sofia
}

\begin{abstract}
BACKGROUND: The performance of multivisceral resections in cases of locally and systematically advanced colorectal cancer has its own place in the treatment of this disease. This approach is usually used in young patients as a part of two-stage surgical strategy or combined with adjuvant chemotherapy to achieve the re-staging of systemic metastases. Avoiding colostomy and better quality of life is a strong motive to move in this direction.
\end{abstract}

AIM: To determine the indications and early postoperative results in a group of patients with locally and systemically advanced colorectal cancer with multivisceral resection of a local disease.

MATERIALS AND METHODS: For a period of 8 years 2007 - 2014, 27 patients with distant metastases underwent local multivisceral resection. For the same period a total of 191 patients were operated for locally advanced CRC. All methods for early postoperative results assessment were used.

RESULTS: The average age in the group was 64 years. The perioperative mortality rate was $3.7 \%$ and the morbidity was $\mathbf{1 4 . 8 \%}$. We performed colostomy in only 3 cases.

CONCLUSION: Aggressive surgical attempt is justified in selected patients and it is connected with low mortality and morbidity rate. The quality of life is a strong reason for such therapeutic strategy.

Keywords: palliative, colorectal, multivisceral

\section{INTRODUCTION}

During this study, surgical patients with locally advanced colorectal cancer were analyzed and compared with early perioperative results in a separate group of patients with local and systemic advanced disease. Both groups underwent multivisceral resections and the primary disease was removed. This approach was used in the presence of complications of the disease in proven distant metastases requiring surgery, as well as in selected patients.

Address for correspondence:

Vesselin Marinov

51 B Nikola Vaptsarov Blvd

$4^{\text {th }} \mathrm{fl}$. Surgery Dept.

Tokuda Hospital Sofia

1612, Sofia, Bulgaria

e-mail:vesika_m@mail.bg

Received: November 15, 2015

Accepted: February 12, 2016

\section{MATERIALS AND METHODS}

For a period of 8 years, January 01, 2007 - December 31, 2014, 191 patients with locally advanced colorectal cancer were operated on. 27 patients with distant metastases underwent multivisceral resections. We used all clinical, laboratory, imaging, instrumental, mortem, etc. research methods. Retroand partially prospective analysis of perioperative results for the period of 8 years was made.

\section{RESULTS}

The distribution by sex and age of the patients in the study group is characteristic of the disease. The average age was 64.1 y.o. It is approximately the same for both sexes - 14 (52\%) men and 13 (48\%) in women. The locations of the primary process are shown in Table. 1. 
In more than half of patients the process was localized in the left colon and the rectum - 16 (59\%). metastases from carcinoid GI and metachronous locally advanced colon cancer. The biggest group of pa-

Table 1. Locations of the primary process

\begin{tabular}{l|ccc|cc|c|c} 
Right colon & $\begin{array}{c}\text { Right } \\
\text { flexure }\end{array}$ & $\begin{array}{c}\text { Transverse } \\
\text { colon }\end{array}$ & $\begin{array}{c}\text { Left } \\
\text { flexure }\end{array}$ & $\begin{array}{c}\text { Descendent } \\
\text { colon }\end{array}$ & $\begin{array}{c}\text { Sigmoid } \\
\text { colon }\end{array}$ & $\begin{array}{c}\text { Sigmoid } \\
\text { rectal area }\end{array}$ & Rectum \\
\hline & 2 & 3 & 2 & 1 & 10 & 1 & 4 \\
\hline
\end{tabular}

The distribution of the remaining locations was almost equal. The greatest frequency of the primary process has been determined to be in the area of the sigmoid colon. Table 2 shows the involvement of adjacent organs and anatomical structures of the disease.

tients was with liver metastases - 21 (77.7\%). Multiple metastases involving the right lobe with relatively low volume segments II, III were diagnosed in two of them.

Complications were established in the ma-

Table 2. Involvement of adjacent organs and anatomical structures of the disease

\begin{tabular}{l|cll}
\hline Parietal peritoneum & 15 & Adnexa & 2 \\
Urinary bladder & 4 & Large bowel & 2 \\
Liver & 1 & Adipose capsule of kidney & 4 \\
Pancreas & 1 & Small bowel & 3 \\
Spleen & 2 & Vagina & 1 \\
Mesenterium & 2 & Presacral fascia & 1 \\
Gall bladder & 1 & D. deferens & 1 \\
Appendix & 1 & & \\
\hline
\end{tabular}

In all cases in the study group distant metastases were diagnosed, the systemic dissemination has often been combined - haematogenous/lymphogenic/peritoneal. Metastases shown in Table 3.

Table. 3. Metastases

\begin{tabular}{l|cll} 
Lungs & 6 & Multiple peritoneal & 4 \\
Virchow's mets. & 1 & Pulmonary carcinoid mets. & 1 \\
Multiple or bilobar liver & 17 & Bilobar solitary liver & 2 \\
Liver - segments- IV-VIII,I & 2 & & \\
\hline
\end{tabular}

Extraperitoneal systemic metastases were diagjority of the patients at the time of diagnosis: anemia - 13; rectal hemorrhage - 8 ; relative bowel obstruction - 6; ileus - 2; sigmoid-vesical fistula - 1; ascites -8 .

All patients underwent colonic resection, renosed in eight patients, one of them has proven lung gional lymphadenectomy and excision/resection of Table. 4. Surgical interventions

\begin{tabular}{l|l} 
Surgical interventions & Number \\
\hline Right resections with anastomosis & 6 \\
Left resections with anastomosis & 14 \\
Subtotal colectomy with anastomosis & 3 \\
Hartmann's resections + ligation of right portal vein. & 1 \\
Miles' + liver metastasectomy, residual pulmonary met. & 1 \\
Transverse colon resection + ligation of the right hepatic artery & 1 \\
Hartmann's resection in a total large bowel obstruction & 1 \\
\hline
\end{tabular}

Scripta Scientifica Medica, vol. 48, No. 1, 2016, pp. 26-29 
the affected neighboring organs/anatomical structures without breaking the adherent to the tumor surface. The surgical interventions are presented in Table 4.

Adjacent anatomical structures and organs resected during multivisceral surgery are shown in Table 2 .

As it is apparent from Table 4, in only three patients the operation is ended with the exteriorization of the colon.

In one patient the Hartmann's resection and partial resection of bladder with ligation of the right portal branch were performed in an attempt to increase the volume of the left lateral segment of the liver and the two-stage operation.

In one patient - multivisceral Miles' resection and pre-sacral fascia/vagina/liver metastasectomy were performed. Residual solitary pulmonary metastases were subsequently targeted for adjuvant chemotherapy therapy and possible pulmonary resection.

In the last patient, Hartmann's resection a modo and an excision of the parietal peritoneum in a case of ileus were performed. In all other cases, the continuity of the gastrointestinal tract was preserved. In the study group, one patient died (3.7\%) with evidence of liver and kidney failure. Perioperative complications were observed in 4 patients (14.8\%). The average hospital stay was 8.2 days. Histological infiltration of neighboring organs/anatomical structures was found in 22 patients (87.5\%). In 5 patients (18.5\%) the case was adhesion of peritumoral inflammation.

\section{DISCUSSION}

Radical resection has been proven to be the most effective treatment of colorectal cancer (1). At the time of the diagnosis, however, in about 20\% of patients it is impossible to perform radical treatment and it is necessary to take palliative measures, most often because of complications or high risk of occurrence of such $(2,3)$. Because these are elderly patients with poor performance status, who presented with a lot of comorbidities, the question is - is the removal of the primary tumor accompanied by a prolongation of the patient's life $(2,4-9)$ ? Obstructive complications were observed in 10-29\% of patients with advanced colorectal cancer at the time of the diagnosis (10). Pazzini and coll. report a group of 8 patients (29.6\%) with a clinic of relative or complete intestinal obstruction at the time of the diagnosis. There are no set rules of surgical behavior in the treatment of locally advanced colorectal cancer. Some studies have reported acceptable levels of perioperative morbidity and mortality rates in selected patients who had undergone resection of a primary tumor (9). In the studies of Kleespies et al. perioperative complications amounted to $16.2 \%$ at $2.86 \%$ perioperative mortality. The results in terms of perioperative morbidity, 4 (14.8\%) lethality and 1 (3.7\%) with an average hospital stay of 8.2 days, reported in this publication provide grounds to believe that the removal of the primary tumor in selected patients is the method of choice. Moreover, the combination with adjuvant chemotherapy improves the survival rate (11). Our opinion is that palliative resections prevent obstructive complications, reduce the level of pain and the hemorrhage associated with the disease (12).

\section{CONCLUSION}

Aggressive surgical approach in the treatment of colorectal cancer, even in cases of impossible radicalism in selected patients, is justified. On the one hand modern approaches in ChT give reason to believe that the maximum cytoreduction may prolong survival. On the other, improving the patients' quality of life with acceptable risk is a legitimate argument for aggressive surgical behavior.

\section{REFERENCES}

1. Schmiegel W, Pox C, Adler G, Fleig W, Fölsch UR, Frühmorgen P, et al. S3-Guidelines "Conference Colorectal” Carcinoma 2004. Z Gastroenterol. 2004; 42:1129-1177

2. Ruo L, Gougoutas C, Paty PB, Guillem JG, Cohen AM, Wong WD. Elective bowel resection for incurable stage IV colorectal cancer: prognostic variables for asymptomatic patients. J Am Coll Surg.2003; 196:722-728.

3. Mella J, Biffin A, Radcliffe AG, Stamatakis JD, Steele RJ. Colorectal Cancer Working Group; Royal College of Surgeons of England Clinical Epidemiology and Audit Unit. Population-based audit of colorectal cancer management in two UK health regions. Br J Surg. 1997; 84:1731-1736.

4. Mäkelä J, Haukipuro K, Laitinen S, Kairaluoma MI. Palliative operations for colorectal cancer. Dis Colon Rectum. 1990; 33:846-850. 
5. Liu SK, Church JM, Lavery IC, Fazio VW. Operation in patients with incurable colon cancer--is it worthwhile? Dis Colon Rectum. 1997; 40:11-14.

6. Beham A, Rentsch M, Püllmann K, Mantouvalou L, Spatz H, Schlitt HJ, et al. Survival benefit in patients after palliative resection vs non-resection colon cancer surgery. World J Gastroenterol. 2006; 12:6634-6638.

7. Guba M, Bosserhoff AK, Steinbauer M, Abels C, Anthuber M, Buettner R, et al. Overexpression of melanoma inhibitory activity (MIA) enhances extravasation and metastasis of A-mel 3 melanoma cells in vivo. Br J Cancer. 2000; 83:1216-1222.

8. Costi R, Mazzeo A, Di Mauro D, Veronesi L, Sansebastiano G, Violi V, et al. Palliative resection of colorectal cancer: does it prolong survival? Ann Surg Oncol. 2007; 14:2567-2576.

9. Kleespies A, Füessl KE, Seeliger H, Eichhorn ME, Müller MH, Rentsch M, et al. Determinants of morbidity and survival after elective non-curative resection of stage IV colon and rectal cancer. Int J Colorectal Dis. 2009; 24:1097-1109.

10. Kim JH, Shon DH, Cahng BI, Chung MK, Shim MC. Complete single stage management of left colon cancer obstruction with a new devices. J Korean Soc Coloproctol. 2002; 18:30-36.

11. Costi R, Di Mauro D, Giordano P, Leonardi F, Veronesi L, Sarli L, et al. Impact of palliative chemotherapy and surgery on management of stage IV incurable colorectal cancer. Ann Surg Oncol.2010; 17:432-440.

12. Draganov K, Marinov V, Petreska A, Rusenov D, Kolev Y, Borisov B, Katev N.N, Penchev D, Chengalova G, Lavchev S, Stoyanova D, Tonev S, Gaydarski R. Multivisceral 'en-block' resections of colorectal tumors - milestones in the surgical techniques Scripta Scientifica Medica, vol. 45 Suppl. 2, 2013, pp. 50-57 